\title{
EMIGRAÇÃO CLANDESTINA DURANTE O ESTADO NOVO O fluxo migratório ilegal do sotavento do Algarve para Marrocos
}

Resumo: Este texto analisa a emigração clandestina com origem no sotavento do Algarve, no Estado Novo, para esclarecer: que relação existia entre este fluxo migratório ilegal e outros sistemas emigratórios coetâneos? Quem eram os emigrantes ilegais que dinamizavam este sistema? Que circunstâncias e motivos justificavam a opção destes emigrantes? Foram analisados os dados obtidos num corpus documental constituído por 43 processos-crime instruídos nas comarcas de Faro, Olhão, Tavira e Vila Real de Santo António, por factos relacionados com a emigração ilegal, nos quais foram acusadas 178 pessoas.

No Estado Novo foi crescente o controlo e repressão da emigração clandestina pela polícia de fronteiras, mas isso não impediu os emigrantes ilegais de procurarem trabalho e melhores condições de vida, dinamizando o sistema migratório luso-hispano-marroquino que persistiu a par do sistema transatlântico. Os constrangimentos colocados pelo novo Reino de Marrocos e a emergência do sistema migratório europeu contribuiriam para transmutar o «marroquino»em 0 «francês».

Palavras-chave: Emigração clandestina; sistema emigratório; Estado Novo; Sotavento do Algarve.

\section{ILLEGAL EMIGRATION DURING THE ESTADO NOVO/NEW STATE The illegal migratory flow from the leeward of Algarve to Morocco}

\begin{abstract}
This text analyses illegal emigration originating in Algarve, during the Estado Novo (New State), in order to clarify: what relationship existed between this illegal migratory flow and other contemporary emigratory systems? Who were the illegal emigrants activating this system? What circumstances and motives explained these emigrants' option? Analysis was made of data obtained in a documental corpus of 43 court cases dealt with at the courts of east south Portugal, for facts related to illegal emigration, in which 178 people were accused.

In Estado Novo, there was an increased control of illegal emigration by the border police of the corporatist regime, but the illegal emigrants filled the shortage of labour principally in Morocco and integrated the Portuguese-SpanishMoroccan migratory system, which persisted alongside the transatlantic system. The restrictions introduced by the new Kingdom of Morocco and the emergence of the European migratory system contributed to transform the «Moroccan» in the «Frenchman».
\end{abstract}

Keywords: Illegal emigration, migratory system, Estado Novo/New State, Leeward of Algarve.

\footnotetext{
${ }^{1}$ Mestre em Portugal Islâmico e Mediterrâneo pela Universidade do Algarve (Portugal)

(mari_liv@hotmail.com)

${ }^{2}$ Professora Coordenadora da Universidade do Algarve (Portugal)

Doutorada em Antropologia pela Universidade Nova de Lisboa (aanica@ualg.pt)
} 


\section{Introdução}

A presença constante da emigração na cultura portuguesa, as variações dos fluxos migratórios e as características destes no tempo e no espaço têm reunido nos últimos quarenta anos uma vasta bibliografia ${ }^{3}$, mas o tema continua a suscitar o interesse dos investigadores que procuram novas perspetivas de abordagem e a diversificação das fontes que estas implicam.

Nas mais recentes investigações tem-se procurado a compreensão global do fenómeno pela articulação de diversos níveis de análise, do global ao local, das estruturas e das políticas aos comportamentos dos indivíduos e às suas motivações. $\mathrm{O}$ objeto de investigação alargou-se à emigração clandestina, suscitando atenção redobrada às fontes judiciais e orais, as quais se encontram ainda em boa parte por desbravar. Nesta linha, o presente texto questiona a emigração clandestina com origem no Algarve central e oriental durante o Estado Novo, procurando esclarecer as seguintes questões: que relação existia entre este fluxo emigratório ilegal e outros sistemas emigratórios coetâneos? Quem eram os emigrantes ilegais que alimentavam este sistema? Que circunstâncias e motivos justificavam a opção destes emigrantes? Qual a dinâmica da repressão deste fenómeno ao longo do período considerado?

A procura de resposta a estas questões implicou a constituição de um corpus documental constituído por quarenta e três processos-crime relativos a emigração clandestina, os quais foram instruídos nas comarcas de Faro, Olhão, Tavira e Vila Real de Santo António, nas décadas de 30 a 70 do século XX. Nestes processos foram privilegiados os dados dos autos de notícia e dos autos de corpo de delito, deixando-se para próxima oportunidade outras vertentes do fenómeno que podem ser analisadas a partir de dados constantes nas restantes componentes dos mesmos processos. Foi constituída uma base de dados cujas variáveis foram analisadas com recurso ao programa IBM-SPSS Statistics.

Sublinha-se, desde já, que os cento e setenta e oito acusados nos processos que integram o corpus documental analisado neste estudo não perfazem o universo dos acusados de emigração clandestina ou outros delitos associados a este fenómeno, dado que nem todos os processos deste tipo foram preservados nos arquivos judiciais das comarcas em questão. Apesar desta limitação, considera-se que os processos - examinados numa perspetiva metodológica mista - constituem uma amostra significativa de apreciável valor pela pluralidade dos dados e pela multiplicidade das vozes que os integram.

Procedemos seguidamente à caracterização do contexto geral do fenómeno em estudo.

\section{Enquadramento}

Calcula-se que, entre 1900 e 1988, terão emigrado de Portugal cerca de 3,5 milhões de pessoas, 25\% das quais tê-lo-ão feito de modo ilegal (Baganha, 1994, p. 960). Esta estimativa é baseada tanto nas estatísticas oficiais portuguesas como nas estatísticas da imigração provenientes dos principais países de destino (EUA, França e Alemanha). As estatísticas oficiais portuguesas, bem como as estimativas mais recentes, que estão certamente mais perto da realidade do que as primeiras, não dispensam, no entanto, uma análise crítica ${ }^{4}$, uma vez que não dão conta do retorno e da reemigração, além de que não

\footnotetext{
${ }^{3}$ Para uma perspetiva dos estudos sobre a emigração portuguesa até meados dos anos oitenta, veja-se Rocha Trindade (1984). Sobre novas abordagens, consulte-se Campos e Rocha-Trindade (2005).

${ }^{4}$ Como defende Isabel Tiago de Oliveira (Oliveira, 2007, p. 839) as estatísticas oficiais portuguesas da emigração carecem de análise crítica, nomeadamente de comparação com outros indicadores, como o saldo migratório. Esta autora calcula que emigraram legalmente 109,3 milhares de portugueses na década de 30,90,4 milhares na década de 40, 353,4 milhares na década de 50 e 681 milhares na década de 60.
} 
contabilizam a emigração ilegal para certos destinos, como, por exemplo, aquele que mais nos interessa aqui.

Nas décadas de 30 e 40 do século XX, a uma tendência decrescente do número de emigrantes legais, sucede uma tendência crescente nas décadas de 50 e 60, a qual atinge o máximo histórico de emigrantes no princípio da década de 70. Em meados do século, assiste-se a uma mudança de estrutura dos sistemas migratórios alimentados pelos portugueses: os fluxos deixam de ser predominantemente intercontinentais, para passarem a ser maioritariamente intraeuropeus, tendo-se invertido, novamente, esta tendência a partir de finais dos anos setenta.

Segundo Baganha (1994, p. 962), o volume de emigrantes ilegais terá alcançado 1/3 do total de emigrantes nos anos sessenta e ultrapassado até o número de emigrantes legais na década de 70.0 valor das remessas dos emigrantes relativamente ao valor das exportações subiu de $13 \%$ na década de 50 para $24 \%$ na década de 60, atingindo 56\% nos anos setenta (Baganha, 1994, p. 963), crescimento que mostra a importância da emigração na economia nacional e contribui para explicar a evolução da legislação e 0 resultado da intervenção das instituições de controlo e repressão no fenómeno emigratório.

Os dados relativos à emigração portuguesa e, em particular, os dados respeitantes à emigração ilegal levaram vários historiadores (Baganha, 2003; Pereira, 2002; Pereira, 1981) a questionar o impacto que o Estado Novo terá tido na evolução deste fenómeno, uma vez que as alterações das políticas de emigração neste período não surtiram os efeitos aparentemente pretendidos. Ao longo de quatro décadas, uma política anti-emigração ${ }^{5}$ (1933-1947), que não susteve os emigrantes clandestinos, foi substituída por uma política de quotas ${ }^{6}$ (1947-1962), a qual, apesar de ter como objetivo o melhor controlo do fluxo emigratório, não impediu a emigração ilegal. Por último, foi reconhecida a necessidade de adoção de uma política de abertura $^{7}$ (1962-1974) que se tornou efetiva na primavera marcelista, a partir de 1968.

O primeiro período da política de emigração do Estado Novo, que se prolonga até ao fim da II Guerra Mundial, caracteriza-se pela construção do dispositivo unificado de controlo da emigração baseado na emissão de passaportes segundo critérios específicos de género, idade, nível de instrução e classe socioprofissional, definidos, entre outra legislação, pelo Decreto-lei no 16:782, de 27 de Abril de 1929, e pelo Decreto-lei no 33:918, de 5 de Setembro de 1944. Era vedada a concessão de passaporte ordinário a operários de qualquer indústria ou a trabalhadores rurais, exigindo-se prova de conclusão da $3^{\mathrm{a}}$ classe aos maiores de 14 anos e menores de 45 anos para concessão de passaporte de emigrante. A Polícia de Vigilância e Defesa do Estado (PVDE) ${ }^{8}$ detinha as funções de fiscalização das fronteiras e de repressão da emigração clandestina e das atividades que se desenvolviam em torno da mesma. A Polícia Internacional de Defesa do Estado (PIDE), que lhe sucedeu a partir de $1945^{9}$, detinha, entre outras funções, as administrativas, preventivas e repressivas da emigração clandestina e do aliciamento ilícito.

\footnotetext{
${ }^{5}$ Enquadrada pelo Decreto-Lei no 16:782, de 27 de Abril de 1929 (suspenso sucessivamente, por exemplo, pelo Decreto-Lei $n^{\circ}$ 24:425 de 27 de Agosto de 1934 e pelo Decreto-Lei no 31:650 de 19 de Novembro de 1941) e pelo Decreto-Lei $n^{\circ}$ 33:918 de 5 de Setembro de 1944.

${ }^{6}$ Pelo Decreto-Lei no 36:558, de 28 de Outubro de 1947.

${ }^{7}$ Decreto-lei 44:422, de 29 de Junho de 1962 e decreto-lei 46:939 de 5 de Abril de 1966.

${ }^{8}$ Criada em 1933 pelo Decreto-Lei no 22992, de 29 de Agosto, com competências alargadas, em 1934, pelo Decreto-Lei n ${ }^{\circ}$ 23995, de 12 de Junho, no que respeitava à «repressão da emigração clandestina» e à «luta contra os engajadores».

${ }^{9}$ Criada em 1945 pelo Decreto no 35046, de 22 de Outubro.
} 
O segundo período da política de emigração do Estado Novo, compreendido entre o fim da II Guerra Mundial e os anos 60, caracteriza-se pela criação da Junta de Emigração ${ }^{10}$, cujo objetivo era 0 controlo integral do processo emigratório pelas instituições do Estado. Foi criado um sistema de quotas, que definia um número máximo de partidas por região e profissão, pretendendo-se controlar a saúde e 0 transporte dos emigrantes legais. Previa-se a criação das Casas do Emigrante, em Lisboa e Porto, com a finalidade de «guiar e proteger» os emigrantes «chegados da província para embarque» ou «receber os emigrantes retornados» ${ }^{11}$.

Estas alterações na política de emigração pressupunham o reconhecimento de que a emigração desempenhava a função de «válvula de segurança» para o excesso de população relativamente aos recursos disponíveis. Ao mesmo tempo, procurava-se não pôr em causa os interesses dos grupos que, dentro do regime, se opunham à emigração (Pereira, 2014), revertendo externamente a favor do regime quer a imagem de «proteção» do emigrante (Paulo, 1998), quer as remessas de divisas enviadas pelos mesmos. Estas mudanças enquadram-se nas opções de política económica e de política externa do Estado Novo que privilegiavam a industrialização e a modernização do sistema produtivo nos termos previstos no I Plano de Fomento e a melhoria da imagem internacional do regime autoritário e conservador no novo contexto democrático no pós-II Guerra Mundial.

O terceiro período da política de emigração do Estado Novo, compreendido entre os primeiros anos da década de 60 e 1974, caracteriza-se pelo estabelecimento de acordos bilaterais entre o Estado Português e os Estados de França ${ }^{12}$ (1963), Espanha (1962), República Federal da Alemanha (1964), Luxemburgo (1965), Países Baixos (1966), Argentina (1966), Brasil (1969) e Bélgica (1970), com vista a aliar o controlo do fenómeno da emigração à maximização do retorno económico dos emigrantes, bem como 0 apoio social às famílias dos emigrados. A persistência da emigração ilegal e a elevação da taxa de crescimento e da internacionalização da economia portuguesa terão favorecido a introdução destas mudanças de política emigratória. O Decreto-lei 46939, de 5 de Abril de 1966, agravou as penas para os que aliciassem, ou ajudassem, ou transportassem emigrantes clandestinos, considerando-os crimes punidos com a pena de prisão maior de dois a oito anos, sendo mantidas as penas aplicáveis aos emigrantes clandestinos. Ainda assim, a emigração clandestina continuou a avolumar-se, realidade que coloca questões relativas à coerência entre os objetivos políticos explicitados e as práticas de controlo e repressão dos que atuavam no terreno (Guarda Nacional Republicana e PIDE), como foi evidenciado pelos autores atrás citados (Pereira, 1981; Pereira, 2005, 2002).

Com a substituição de Salazar por Marcello Caetano na chefia do governo, em 1968, foram ultrapassadas as ambiguidades da política de emigração: o crime de emigração clandestina foi amnistiado $^{13}$, seguindo-se a sua descriminalização, em 1969, quando passou a ser considerado contravenção punível com multa de $500 \$ 00$ a $20.000 \$ 00^{14}$. A pena de prisão até dezoito meses e multa ficou reservada ao aliciamento e auxílio «de forma a não agravar excessivamente a diferença entre as penalidades aplicáveis aos autores daqueles actos e aos próprios emigrantes...» ${ }^{15}$. A Junta de Emigração

\footnotetext{
${ }^{10}$ Decreto-Lei $n^{\circ} 36558$, de 28 de Outubro de 1947.

${ }^{11}$ Idem.

${ }^{12}$ Sobre este acordo veja-se Victor Pereira (2002).

${ }^{13}$ Decreto-Lei no 48 783, de 21 de Dezembro de 1968.

${ }^{14}$ Decreto-Lei no 49 400, de 19 de Novembro de 1969.

${ }^{15}$ Idem.
} 
foi extinta, em 1970, dando lugar ao Secretariado Nacional da Emigração ${ }^{16}$, cuja missão era a «disciplina do fluxo migratório para a Europa» e a «assistência aos trabalhadores portugueses no estrangeiro» ${ }^{17}$. Simultaneamente, o governo de Marcelo Caetano procurou atenuar a intensidade do fluxo migratório por meio da melhoria das condições de vida dos mais vulneráveis, com a extensão da previdência social aos rurais e com a concessão do abono de família ${ }^{18}$. De facto, o volume da emigração decresceu ligeiramente, a partir de 1970. A propósito desta relação entre a emergência da segurança social e o ligeiro decréscimo do fluxo emigratório, refere Victor Pereira (2009) que os emigrantes com destino a França eram atraídos não apenas pelo poder de compra mais elevado, mas também pelo sistema de segurança social e pelas perspetivas de ascensão social para os próprios e para os seus descendentes, condições que não existiam em Portugal.

A emigração portuguesa, em especial a emigração clandestina, para além de constituir uma forma de resistência quotidiana às más condições de vida - no sentido de recusa do cumprimento da lei e da adoção de práticas opostas aos discursos do poder dominante - permitia que os emigrados contactassem com realidades sociais promissoras, as quais eram, depois, narradas aos que ficavam, contribuindo para abrir horizontes de possibilidades no país de origem, que viriam a explicar, entre outros fatores, o descrédito do Estado Novo em camadas cada vez mais amplas da população, como Victor Pereira (2009) evidenciou. Por outro lado, a redução da oferta de mão-de-obra, resultante do fluxo emigratório intenso no período final do Estado Novo, concorreu para o aumento do custo do trabalho e para o impacto dos crescentes movimentos de contestação que surgiam nas cidades e nos campos. Marcelo Caetano, à beira de eleições, soube ler estes sinais, o que conduziu à despenalização da emigração clandestina, em articulação com medidas de política social que pretendiam desincentivá-la.

No contexto atrás esboçado, o caso algarvio distingue-se pelas suas especificidades, as quais podemos sintetizar em três pontos: $1^{\circ}$ - a longa persistência do sistema migratório do golfo luso-hispanomarroquino, até aos anos sessenta do século XX; $2^{\circ}$ - a importância da emigração e reemigração temporárias de trabalho; $3^{\circ}$ - a interligação entre o sistema migratório do golfo luso-hispano-marroquino e o sistema migratório transatlântico, no qual se destaca a preferência pelo destino argentino ${ }^{19}$.

No ponto seguinte, inscreve-se a emigração clandestina do sotavento algarvio no âmbito do sistema migratório ${ }^{20}$ do golfo luso-hispano-marroquino, utilizando o conceito proposto por Romero Magalhães $(1970 ; 1988)$.

\footnotetext{
${ }^{16}$ Decreto-Lei $n^{\circ}$ 402/70, de 22 de Agosto.

${ }^{17}$ Decreto-Lei $^{\circ} 15 / 72$, de 12 de Janeiro.

${ }^{18}$ Lei no $^{\circ} 2144$, de 25 de Maio de 1969 e Decreto ${ }^{\circ} 445$, de 23 de Setembro de 1970.

${ }^{19}$ Esta preferência foi crescendo durante a I República e atingiu o máximo nos anos 40, atraindo a Argentina 2/3 dos emigrantes legais com origem no Algarve (Borges, 2009).

${ }^{20}$ Sistemas migratórios são fluxos recorrentes de migrações que ligam regiões ou estados com estruturas demográficas, económicas e culturais diferentes. Os fluxos migratórios incluem emigração, imigração, retorno e reemigração. Estes fluxos sustentam redes de interação que atuam como veículos de informação, assistência e cooperação que ligam os migrantes ao sistema (Borges, 2009, pp. 73-75). Os sistemas migratórios são dinâmicos e flexíveis, emergem, adaptam-se e podem desaparecer em função de mudanças internas ou externas, podendo coexistir e interagir com outros sistemas. Como tem sido assinalado, este conceito é uma ferramenta apropriada para a análise processual e sistémica das migrações, permitindo relacionar o local com o global, as especificidades nacionais, regionais, locais e individuais com as estruturas internacionais (Moch e Hoerder, 1996). Numa outra linha das investigações, colocou-se o foco nas estratégias de sobrevivência, nas práticas culturais e na construção de identidades e propôs-se o conceito de transnacionalismo para significar os processos pelos quais os migrantes (transnacionais) constroem campos sociais que ligam o seu país de origem ao país de acolhimento, tomando decisões, atuando e desenvolvendo sentimentos e identidades no âmbito de redes sociais que articulam uma ou mais culturas simultaneamente (Basch, Schiller e Blanc-Szanton, 1999).
} 


\section{Persistência do sistema migratório do golfo luso-hispano-marroquino}

A participação dos algarvios no sistema migratório luso-hispano-marroquino remonta pelo menos ao princípio da época moderna ${ }^{21}$, senão mesmo à época medieval ${ }^{22}$, mantendo-se ativa até meados dos anos cinquenta do século XX. Na época contemporânea, os fluxos migratórios para o Alentejo, Andaluzia, Gibraltar e Marrocos, principalmente os sazonais, eram dominados pela migração algarvia, tendo a sua relevância económica e social aumentado ao ponto de o poder político ser levado a prescindir do passaporte para efeito de trabalho sazonal em Espanha, substituindo-o pelo salvo-conduto no último quartel do séc. XIX.

Relativamente ao século XX, Arnaldo Anica (2008) assinalou o registo de 184 emigrantes sazonais no curto período dos três primeiros meses de 1923, nos Termos de Abonação do Concelho de Tavira $^{23}$, sendo 81 destinados a trabalhos agrícolas a realizar em diversas localidades do Sul de Andaluzia, entre Aiamonte e Gibraltar, e 103 destinados a trabalhos relacionados com a pesca a desenvolver entre Aiamonte e Cádis. ${ }^{24}$

Por seu turno, Carminda Cavaco (1971, pp. 41-83) contabilizou 3482 contratos de trabalhadores do sotavento algarvio para trabalhos temporários em armações de atum e em fábricas de conservas de peixe localizadas principalmente em Marrocos e Tunísia, mas também no sul de Espanha, entre 1933 e 1952. A pesca e as indústrias de conserva de peixe, a agricultura e a mineração eram os principais setores da economia que animavam a atividade económica neste sistema migratório (Cavaco, 1976; Costa, 2002).

A face legal do sistema migratório luso-hispano-marroquino é melhor conhecida do que a face ilegal do mesmo sistema. Ainda assim, sabe-se que, durante o século XIX, o contrabando se fazia intensamente pelas rotas terrestres e pela marítima, sendo plausível que a emigração ilegal andasse aliada àquela atividade. Por via terrestre, os muares faziam o transporte das mercadorias até ao rio Guadiana, sendo o momento de atravessar o rio o mais crítico no conjunto das operações que envolviam geralmente contrabandistas apoiados em forças de retaguarda, as quais preparavam frequentemente emboscadas aos guardas alfandegários portugueses. Azinhal era o ponto privilegiado de passagem ilegal de peles, tabaco, cavalos, pólvora, fio, sabão, trigo, redes e açúcar. Por via marítima, chegavam ilegalmente à costa algarvia, provenientes de Gibraltar e Huelva, grandes quantidades de tabaco mas também de manteiga, papel, trigo, bacalhau, chá, lona, sapatos, cartas de jogar, fazendas, genebra e outras bebidas, ferros de engomar e lençóis. Esta diversidade de mercadorias tanto podia ser objeto de contrabando em larga escala, envolvendo embarcações estrangeiras apoiadas em recetadores nacionais, como podia envolver pequenas embarcações nacionais que pescavam e mercadejavam desde a costa algarvia até ao estreito de Gibraltar (Anica, 2001, pp. 103-115).

\footnotetext{
${ }^{21}$ Joaquim Romero Magalhães (1970, p.223) afirma que «um dos traços característicos do Algarve, factor que lhe marca individualidade adentro do conjunto da terra portuguesa, é a actividade marítima e a solidariedade geográfico-económica dos Algarves luso-hispano-marroquinos que formam o golfo de Gibraltar».

${ }^{22}$ Oliveira Marques explica como foi resolvida a crise do pão no Algarve recém-reconquistado pelos cristãos: «A primeira referência concreta que possuímos sobre importação cerealífera em Portugal encontra-se num documento dos finns do século XIII. Conquistara-se o Algarve havia três décadas; a interrupção momentânea do tráfico com o Islão peninsular e africano paralisara os fornecimentos de pão à província, sempre escassa nele. $\mathrm{O}$ rei fora obrigado a emprestar trigo dos seus celeiros para o abastecimento de algumas praças-fortes; em 1282, assistimos a uma tentativa de normalizar a situação, permitindo de novo o intercâmbio com a mourama» (Marques, 1968, p. 156).

${ }^{23}$ Previstos no Regulamento Geral dos Serviços de Emigração publicado a 19 de Junho de 1919.

${ }^{24}$ Agradecemos ao autor o acesso ao texto original da comunicação.
} 
O sistema migratório luso-hispano-marroquino encontrava-se interconectado com o sistema transatlântico, uma vez que o porto de Cádis servia a ligação do sul da Península Ibérica aos portos do continente americano, sendo por isso porto de embarque para os que pretendiam alcançar o outro lado do Atlântico (Borges, 2009).

Na terceira década do século XX (1920-1929), a maioria dos emigrantes algarvios legais tinha como destino a Argentina (59\%), seguindo-se a Europa (12,8\%), o Brasil (12,4\%), os EUA (8,8\%). África (sem mais especificações) surgia em quinta posição $(6,0 \%)$. Já nos anos 30, o padrão mudara: Argentina continuava a ser o destino preferido (36,3\%), mas África saltara para o segundo lugar (26\%), logo seguida da Europa (25,8\%). Nos anos sessenta, o sistema migratório do noroeste europeu já predominava sobre o sistema transatlântico na emigração algarvia, tal como no resto do país, com a França a reunir 2/3 dos pedidos de passaporte apresentados no Algarve (Baganha, 2003; Borges, 2009). Por essa altura, a independência de Marrocos criara as condições para muitos emigrantes algarvios retornarem à origem ou optarem pela remigração, a partir do Algarve ou de Marrocos, tendo como destino a França.

Para sintetizar, realça-se que a persistente presença da emigração e as transformações deste fenómeno ao longo de séculos correspondem às metamorfoses do emigrante como símbolo da cultura portuguesa: este, de «navegador», passou a «colono» e a «brasileiro», para chegar a «francês», como Bretell (2003) observou. Todavia, no caso do Algarve avulta a figura do «marroquino» que, situando-se cronologicamente entre 0 «argentino» e 0 «francês», reflete a especificidade do fenómeno migratório no sul do país.

Passamos seguidamente a analisar a dinâmica da emigração ilegal no âmbito do sistema lusohispano-marroquino durante a vigência do Estado Novo.

\section{Dinâmica da emigração ilegal}

Como referimos, na primeira metade do século XX, embora os algarvios emigrassem legalmente sobretudo para o continente americano, com preferência pela Argentina, o mesmo não sucedia com os emigrantes ilegais que faziam outras opções. Um conjunto de fatores explica a preferência por destinos geograficamente mais próximos, entre os quais se encontram o conhecimento do espaço, o estabelecimento de longa data de relações sociais e económicas com as gentes destas regiões e os limitados recursos financeiros disponíveis para investir no projeto migratório.

O corpus reunido para este estudo compreende o total de 178 acusados de crimes, sendo a maioria por emigração clandestina $(89,3 \%)$ e os restantes por aliciamento à emigração clandestina $(8,4 \%)$ e por aliciamento e transporte de emigrantes ilegais $(2,2 \%)$. 0 total de acusados corresponde apenas a uma pequena parte dos que partiram e dos que aliciaram a partir, ilegalmente, realidade que os próprios processos demonstram, uma vez que os arguidos, ao serem questionados nos autos, referem com frequência o seu historial de emigração e a existência de outros emigrantes ilegais, que haviam partido com idêntico destino, utilizando os mesmos meios de transporte. Por outro lado, sabe-se que o sistema de controlo e repressão da emigração clandestina variou no grau de eficácia ao longo do período considerado, subsistindo uma cifra negra relativa a este fenómeno que não é possível contabilizar nas fontes analisadas.

Atendendo aos processos-crime compulsados, os quais são relativos a factos ocorridos nas comarcas de Vila Real de Santo António, Tavira, Olhão e Faro, no período do Estado Novo, verifica-se 
que a emigração clandestina nesta região não se desenvolveu de forma linear, apresentando fases distintas e incidências específicas que se caracterizam a seguir resumidamente.

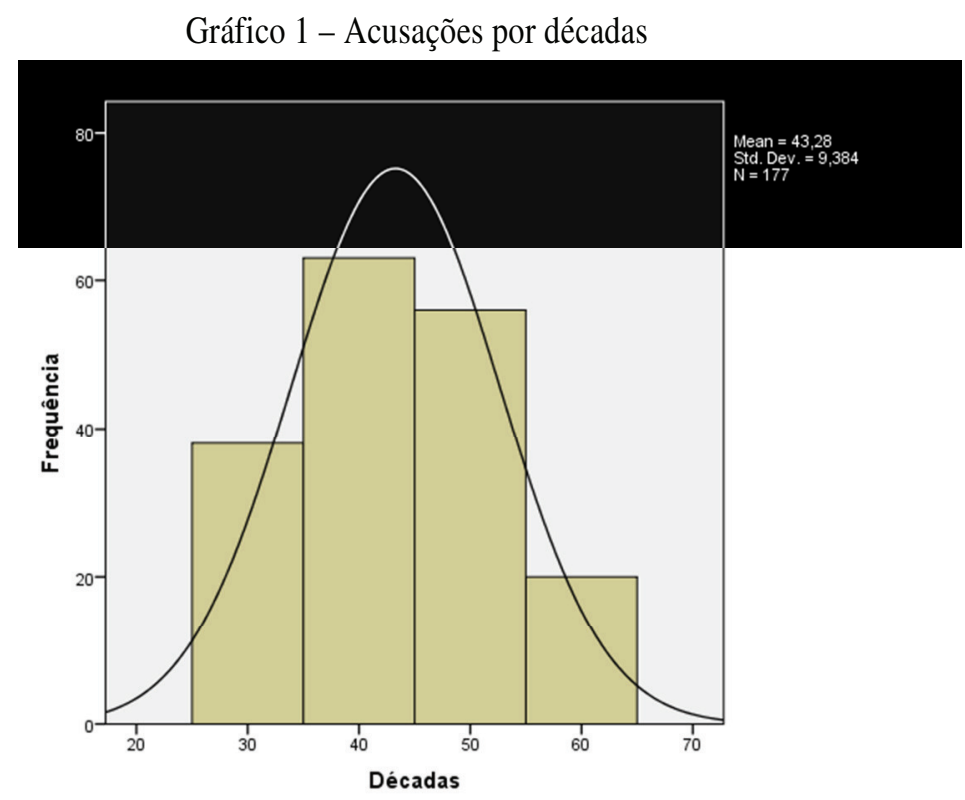

Gráfico 2 - Acusados por ano e país de destino

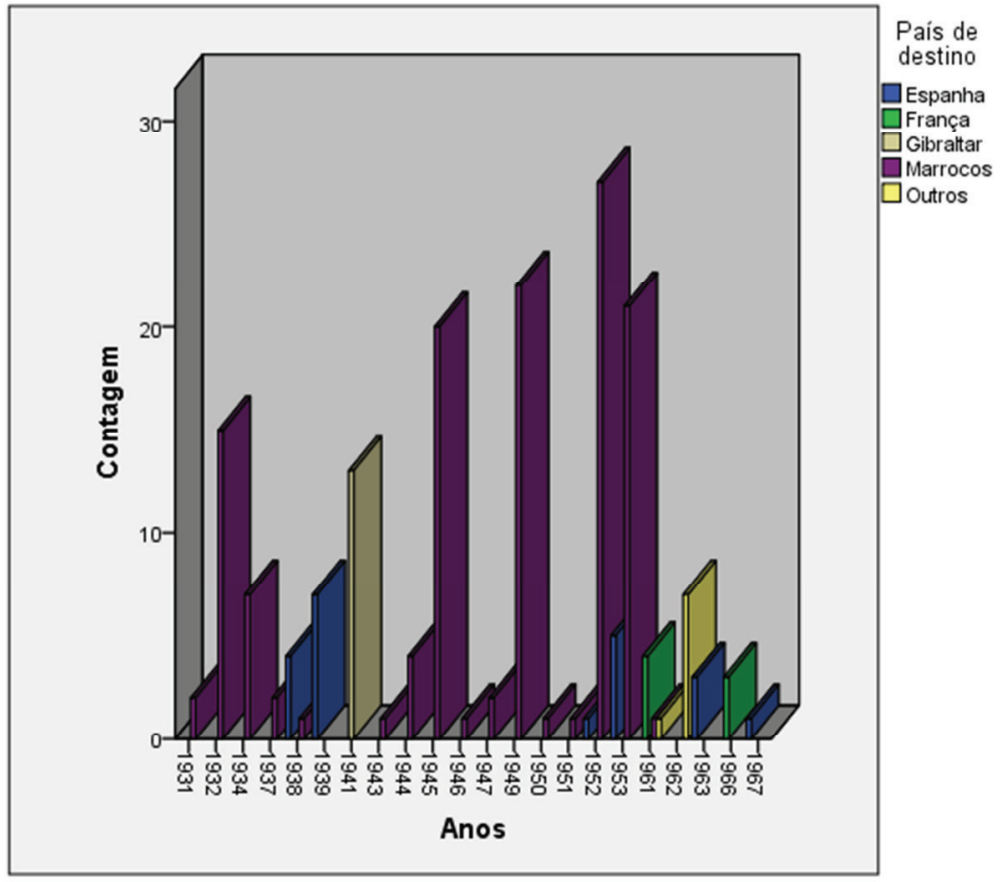


Considerando a evolução do número de acusados, por ano da prática de factos relativos à emigração clandestina no âmbito do sistema luso-hispano-marroquino (gráfico 1), verifica-se que 0 fenómeno começa a avolumar-se nos anos trinta, alcançando o máximo na década de 40, para decair significativamente na década de 60 . Os mesmos dados permitem inferir que o máximo de intensidade da repressão do fenómeno da emigração clandestina ocorreu nas décadas de 40 e 50. A partir de 1954, decai o número de pessoas envolvidas em processos judiciais desta natureza e desaparecem mesmo os casos relativos a emigração clandestina para Marrocos (gráfico 2). Este último facto resulta das dificuldades crescentes que eram colocadas aos emigrantes ilegais no destino, o que se compreende no contexto da independência de Marrocos (1956). Por outro lado, como já referimos, nos anos sessenta o Estado Novo privilegiou a repressão do crime de aliciamento e acabou por despenalizar a emigração clandestina (1968), o que não poderia deixar de se refletir na frequência das acusações.

O fluxo da emigração clandestina no período em análise encaminhava-se predominantemente para Marrocos (73\%), seguindo-se Espanha (12\%) e Gibraltar (7\%). Em Marrocos, as fontes referem-se aos destinos Casablanca, Rabat, Quenitra, Tânger e Fez. Em Espanha, estão documentados os destinos andaluzes Aljaraque, Ilha Cristina, Figueirita e Huelva. França surge como destino alternativo a Marrocos, mas apenas a partir de meados da década de 50 (4\%).

Os destinos da emigração ilegal variavam em função da naturalidade dos envolvidos. Com efeito, os naturais dos concelhos de Faro, Tavira e Olhão preferiam o destino Marrocos e só em segunda linha optavam por diversos locais do sul de Espanha, ao passo que com destino a Gibraltar preponderavam os naturais de Olhão.

A emigração clandestina era favorecida pela localização dos portos de saída e pelas condições climatéricas, como os dados revelam. As viagens eram programadas para os meses quentes de primavera-verão, reunindo o mês de agosto a maioria das saídas (57\%), as quais eram predominantemente feitas por via marítima. Utilizavam-se barcos dos mais variados tipos, desde a canoa, o caíque e o veleiro, até às embarcações a motor de menor deslocamento. A área dos portos de Olhão e de Tavira eram o lugar privilegiado para as manobras dos barcos envolvidos na emigração clandestina, o que não surpreende dadas as dificuldades económicas dos homens do mar e a sua especialização na pesca ao largo, em especial no que respeita ao porto de Olhão, o que lhes facultava vasta experiência de navegação nas águas do golfo de Cádis. O conjunto destas condições favorecia tanto a emigração ilegal, como a atividade de transporte de emigrantes clandestinos. Com efeito, o porto de Olhão fornecia $44 \%$ dos emigrantes ilegais, Tavira era o segundo porto mais importante, com $35 \%$ das saídas, seguindo-se o porto de Faro, com 11\%.

Considerando o local de residência dos emigrantes ilegais, verifica-se que não eram apenas os moradores dos portos atrás referidos que faziam uso das condições que os mesmos ofereciam à emigração ilegal. O concelho de Loulé fornecia $10 \%$ dos emigrantes ilegais, que deixavam o país a partir dos portos do sotavento do Algarve, disponibilizando Vila Real de Santo António mais 5\%. Todavia, a capacidade de atração de emigrantes ilegais pelos portos do sotavento do Algarve irradiava a residentes em Lisboa, Portimão e Silves.

Os dados permitem inferir também que a repressão da emigração clandestina incidia principalmente nos emigrantes com destino a Marrocos, o que se interpreta como reflexo da maior intensidade deste fluxo, ao qual se seguia, por ordem decrescente, o fluxo destinado ao sul de Espanha e a Gibraltar. Emigravam principalmente os homens residentes dos centros portuários do litoral central e 
oriental do Algarve, mas, como já foi referido, o litoral ocidental do Algarve, o barrocal e a serra não deixavam de oferecer o seu contributo para engrossar a sangria de gentes.

No ponto seguinte, traça-se o perfil dos atores sociais envolvidos no sistema migratório ilegal lusohispano-marroquino, durante o período considerado.

\section{Caracterização dos atores sociais \\ Estrutura etária e de género}

Uma característica sobressai: emigrava-se na idade adulta. A faixa etária mais ativa situava-se entre os 25 e os 34 anos (38\%), no entanto o fenómeno envolvia pessoas de todas a idades, desde os jovens até aos mais idosos. Os jovens e os jovens adultos (dos 15 aos 24 anos) também tinham um peso significativo na emigração ilegal (32\%). Seguia-se a faixa etária dos 35 aos 44 anos que representava $21 \%$ dos emigrantes ilegais. Estes números realçam a forma como a emigração clandestina estava enraizada no quotidiano dos algarvios que a praticavam como parte da estratégia familiar de melhoria das condições de vida ou como recurso para garantir a sobrevivência. Quem emigrava era pobre e desprotegido ou pretendia acrescentar aos seus limitados meios um complemento, o qual podia ser obtido tanto por meio da migração interna como por meio da emigração. Tratava-se de procurar uma alternativa, com caráter mais ou menos urgente e temporário, ao desemprego ou a insuficientes meios de subsistência.

No que respeita às mulheres, distingue-se o predomínio de idades mais avançadas do que as dos homens, nomeadamente na faixa etária dos 45 aos 54 anos, o que não é contraditório com as características da emigração feminina a seguir apresentadas.

A emigração clandestina visível nos processos judiciais era um fenómeno predominantemente masculino, embora as mulheres não estivessem ausentes: no conjunto dos envolvidos $90 \%$ eram homens e $10 \%$ eram mulheres. De forma distinta dos homens, cerca de 1/4 das mulheres que emigravam clandestinamente tinham como destino Espanha, dirigindo-se as restantes para Marrocos. Elas emigravam juntamente com os maridos ou pretendiam juntar-se a eles, procurando o reagrupamento familiar.

\section{Estrutura socioprofissional}

As profissões dos envolvidos na emigração clandestina eram diversificadas, inserindo-se em todos os setores de atividade económica. A emigração ilegal era alimentada pelo setor primário (42\%), no qual predominavam os «marítimos» (26\%) - isto é, os pescadores, mariscadores, aqueles que viviam do mar e os «trabalhadores», conceito geralmente utilizado para designar os assalariados rurais (11\%). Seguiase, muito de perto, o setor secundário (41\%), no qual se destacavam os pedreiros (15\%), os carpinteiros (11\%), os serralheiros (6\%) e uma enorme diversidade de outras profissões de cariz mais artesanal do que industrial. Os que desenvolviam atividades no setor dos serviços não alcançavam mais do que $17 \%$ no conjunto dos emigrantes ilegais.

As mulheres declaravam ser «domésticas», com exceção de uma que declarou ser «trabalhadora».

A origem socioprofissional dos emigrantes ilegais condicionava a escolha do país de destino: entre os emigrantes que escolhiam Gibraltar predominavam os «marítimos»; os «trabalhadores» preferiam Espanha; o fluxo para Marrocos, sendo o mais intenso, era também o mais diversificado (gráfico 3). 
Gráfico 3 - Profissões dos emigrantes ilegais por país de destino $(\geq 2 \%)$

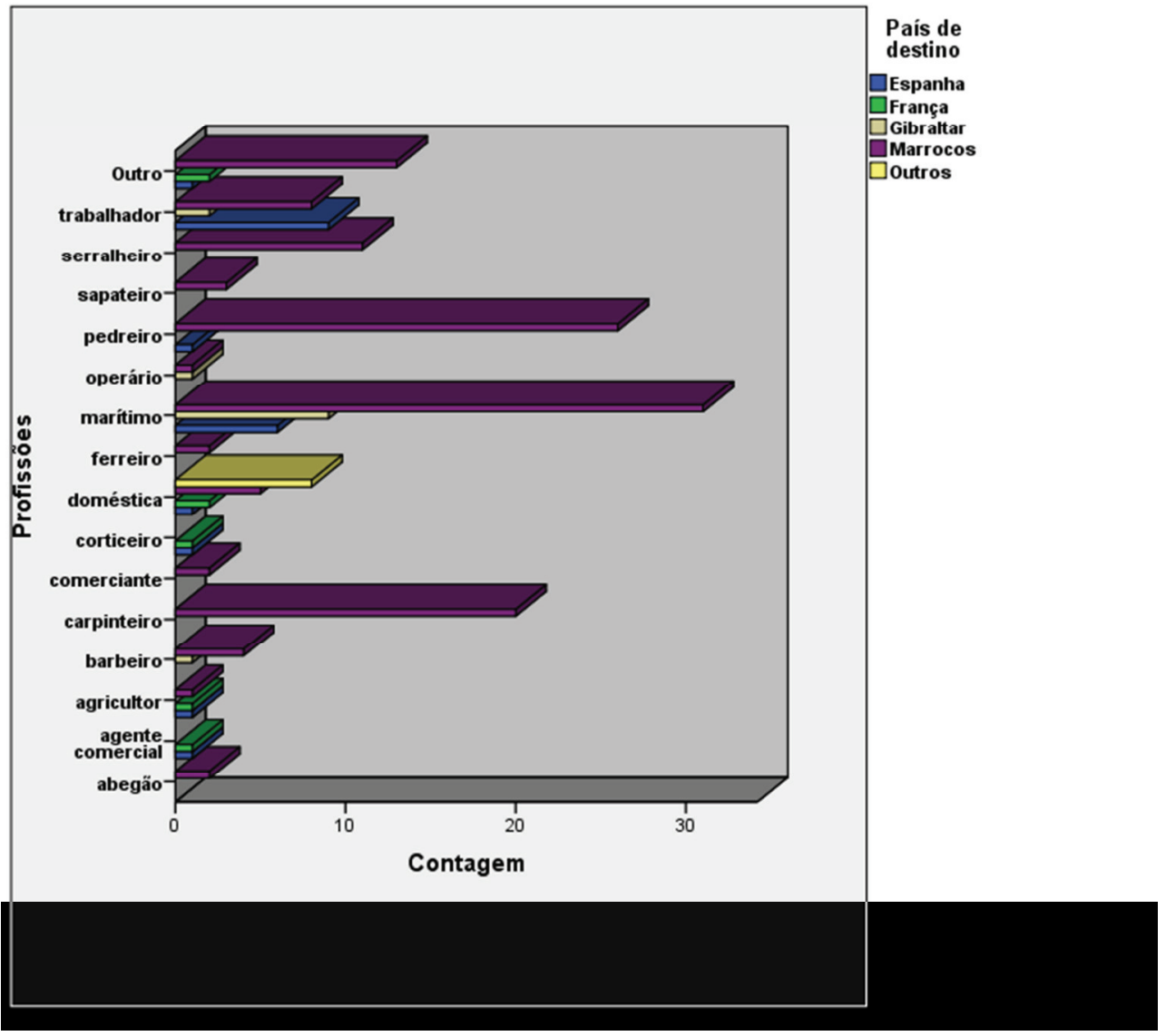

\section{Estado civil}

O estado civil dos indivíduos envolvidos na emigração clandestina é um elemento significativo para a compreensão deste fenómeno. A maioria dos implicados na emigração ilegal era de casados, correspondendo a cerca de $61 \%$ do total. Os solteiros representavam $36 \%$ e os viúvos apenas a $3 \%$. Estes dados sugerem que a pressão das dificuldades económicas, que tendia a aumentar com as responsabilidades familiares, e o desejo de reunir condições para constituir uma estrutura familiar autónoma seriam os fatores mais relevantes da motivação para a emigração clandestina.

\section{Habilitações literárias}

No que concerne às habilitações literárias dos acusados, verifica-se que os indivíduos considerados completamente analfabetos pelas entidades judiciais correspondiam a $29 \%$ do total, sendo que $68 \%$ sabiam escrever o nome, podendo alguns destes saberem ler e escrever. Considerando a relação entre 0 género e as habilitações literárias, apura-se que no total dos acusados surge uma percentagem mais elevada de mulheres analfabetas (59\%) do que de homens na mesma condição (29\%). No grupo masculino dos envolvidos na emigração clandestina, a maioria é dos que sabem assinar (62\%), sendo a percentagem dos completamente analfabetos de $26 \%$. Os valores atrás indicados não são muito díspares da realidade nacional que apresentava taxas elevadíssimas de analfabetismo, principalmente na população feminina. Com efeito, no fim do Estado Novo (1970), a taxa de analfabetismo da população 
portuguesa maior de dez anos era de $64 \%$ nas mulheres e de $34 \%$ nos homens ${ }^{25}$. Todavia, a diferentes papéis desempenhados no processo emigratório clandestino correspondiam níveis de escolaridade distintos. Assim, por exemplo, quando são considerados apenas os acusados de crime de aliciamento, predominam as mulheres, quer do ponto de vista numérico, quer do ponto de vista do nível de literacia.

\section{Género e papéis sociais}

A emigração clandestina a partir do Algarve é substantivada pela existência de um conjunto de atores que se relevam nesta análise. De acordo com a tipologia dos crimes previstos na lei, os atores podiam desempenhar os papéis de emigrantes clandestinos, aliciadores (ou engajadores) e transportadores.

Os vários condicionalismos dos intervenientes no sistema migratório clandestino favoreceram a diferenciação dos papéis dos seus atores diretos. Os engajadores atribuíam-se a principal função de obter documentação falsa, uma das operações comerciais de que vivia o seu negócio. A troco de muito dinheiro, que o pobre cliente arranjava nas suas míseras economias ou recorrendo a um familiar ou amigo, os engajadores tratavam de passaportes, os quais geralmente não chegavam a aparecer, exigindo o pagamento do serviço em dinheiro aos potenciais emigrantes.

Os transportadores encarregavam-se de assegurar o transporte dos emigrantes clandestinos de forma organizada, o qual, como já foi referido, era feito principalmente por via marítima, com destino ao sul de Espanha, a Gibraltar e a Marrocos.

$\mathrm{O}$ aliciamento e transporte podiam ser garantidos pela mesma pessoa, mas também se encontram processos em que os acusados de aliciamento não coincidem com os acusados de transporte, isto é, processos que revelam uma maior complexidade das redes de emigração clandestina. Como já foi referido, identifica-se uma diferença de género no desempenho dos vários papéis, uma vez que as mulheres assumiam maior peso numérico no aliciamento, ao contrário do que acontecia nos restantes papéis em que predominavam os homens.

A diferença de género encontra-se igualmente no grau de literacia dos envolvidos no processo: a maioria das mulheres acusadas de emigração clandestina eram completamente analfabetas, ao invés do que sucedia com as mulheres acusadas de aliciamento. Pelo contrário, a maioria dos homens acusados de emigração clandestina sabiam pelo menos assinar.

Os homens envolvidos na emigração clandestina não pretendiam evadir-se do cumprimento do serviço militar, como aconteceu a muitos portugueses e algarvios de então, principalmente na década de sessenta, quando recusavam a mobilização para as guerras de África. Pelo contrário, os processos revelam que os emigrantes clandestinos chegavam a regressar para «servir a pátria». Estas circunstâncias apontam para uma emigração motivada principalmente por fatores de natureza socioeconómica, como se revela no ponto seguinte.

\section{Circunstâncias e motivações da emigração}

Para os emigrantes ilegais as condições eram duras e os riscos elevados. O fenómeno da emigração, em particular o da emigração clandestina, estava associado aos mitos do retorno e do enriquecimento rápido, mitos que prosperavam numa sociedade hierarquizada, caracterizada por uma

\footnotetext{
${ }^{25}$ População residente analfabeta com 10 e mais anos segundo os Censos: total e por sexo. Fontes de Dados: INE - X, XI, XII, XIII, XIV e XV Recenseamentos Gerais da População. PORDATA.
} 
reduzida mobilidade social, na qual a expatriação surgia como instrumento de sobrevivência e de ascensão social. A saída do país era encarada como temporária, sendo na realidade frequentemente temporária, mas indispensável à acumulação de recursos que permitiriam a alteração do estatuto socioeconómico do emigrante.

No caso dos emigrantes clandestinos presentes nos processos estudados neste trabalho, que nos oferecem uma imagem significativa do fenómeno da emigração algarvia, salienta-se que a maioria emigrava, segundo as suas próprias declarações, por motivos de, por ordem decrescente: «procura de melhor trabalho», expressão muito genérica, que poderia englobar significados semelhantes aos de algumas das categorias seguintes (38\%); desemprego (37\%); insuficiente remuneração (6\%); «pouco trabalho» (4\%); «viver melhor», isto é, procura de melhor qualidade de vida (3\%); «juntar-se à família», ou seja, reagrupamento familiar (2\%). Além dos motivos apontados, surge ainda uma justificação de natureza diferente das anteriores que remete para o desejo «de conhecer outras terras» $(1 \%)^{26}$.

No contexto motivacional atrás referido, o processo de organização da viagem de ida tanto podia caber aos próprios emigrantes, que se associavam e quotizavam para cobrir o investimento inicial indispensável à compra de uma pequena embarcação, como podia ser entregue às redes de «aliciamento e transporte» que, com diferentes dimensões e recursos, operavam a partir do Algarve oriental ou, mais raramente, faziam aí escala.

Em suma, os algarvios desenvolveram estratégias de resistência às dificuldades do quotidiano durante o Estado Novo, entre as quais avultou a emigração que alimentou dois sistemas migratórios contemporâneos: o sistema luso-hispano-marroquino e o sistema transatlântico.

No âmbito do sistema luso-hispano-marroquino, os emigrantes ilegais eram principalmente originários do Algarve oriental, litoral e interior, e procuravam sobretudo trabalho e melhores condições de vida, desejando construir um futuro mais tranquilo em outras paragens, entre as quais predominava Marrocos. Para alcançarem os seus objetivos, os emigrantes oriundos de vários setores económicos principalmente o artesanal, o piscatório e o agrícola - ultrapassavam os constrangimentos oferecidos pelas leis repressivas do Estado Novo de Salazar e as limitações impostas pelos seus parcos recursos financeiros, suprindo no destino as carências de mão-de-obra na indústria, na pesca, na agricultura e nos serviços. O êxito do empreendimento implicava o desafio do controlo e repressão do estado e a mobilização dos saberes tradicionais, das redes familiares, vicinais e socioprofissionais, bem como a atualização de conhecimentos que eram adquiridos no próprio processo migratório e no contacto com as novas realidades no destino. Neste processo, os emigrantes ilegais revelaram uma notável capacidade de assumir riscos e de desafiar as forças que, de forma crescente nas décadas de 30,40 e 50 procuravam confiná-los em limites que, tradicionalmente, lhes eram estranhos.

O desempenho dos papéis no processo migratório clandestino é distinto segundo o género dos intervenientes, assumindo as mulheres maior relevo no aliciamento à emigração clandestina e os homens maior peso numérico no papel de emigrantes.

As dificuldades colocadas à emigração ilegal pelo novo estado marroquino e a crescente atração pela Europa em desenvolvimento no pós-guerra relegaram para um lugar residual os sistemas migratórios luso-hispano-marroquino e transatlântico, a partir de meados dos anos 50. Ainda assim, os

\footnotetext{
${ }^{26} \mathrm{Em} 9 \%$ dos casos não foram registados os motivos da decisão de emigrar ilegalmente.
} 
emigrantes com origem no Algarve não deixaram de procurar construir no exterior o futuro desejado, tendo-se adaptado às circunstâncias e reinvestido em outros destinos. $\mathrm{O}$ «marroquino» transmutou-se, então, em o «francês».

\section{Fontes}

\section{Arquivo Distrital de Faro (ADF)}

Processos de Polícia Correcional da Comarca de Olhão: nº42/1933; n573/1934; nº1621/1934; nº 895/1935;

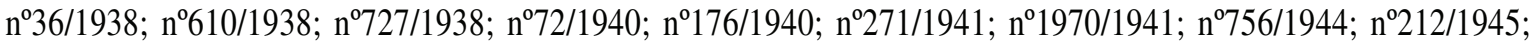
n68/1948; nº6/1948; n²8/1950; nº722/1952; n²8339/1952; nº24/1953; n²6/1953; nº118/1953; nº569/1963; $\mathrm{n}^{0} 447 / 1967$.

Processos de Querela e de Polícia Correcional da Comarca de Faro: $n^{\circ}$ 22/1949; n $^{\circ}$ 201/1964; n 361/1966; n ${ }^{\circ}$ $317 / 1967 ; n^{\circ} 562 / 1967$.

\section{Arquivo Judicial da Comarca de Tavira (AJCT)}

Processos de Polícia Correcional da Comarca de Tavira: $n^{\circ}$ 61/1938; $\mathrm{n}^{\circ} 62 / 1938 ; \mathrm{n}^{\circ}$ 98/1938; nº1433/1944;

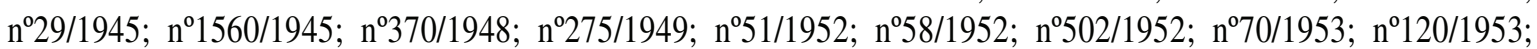
no $865 / 1954 ; n^{\circ} 141 / 1962$.

\section{Referências bibliográficas}

Anica, A. (2001). A transformação da violência no século XIX. O caso da comarca de Tavira. Lisboa: Colibri.

Anica, A. (2008). Obstruções e facilidades das autoridades portuguesas nas saídas sazonais dos trabalhadores algarvios para as terras raianas andaluzas, entre 1850 e 1940. Comunicação apresentada nas XIII Jornadas de História da Cidade de Ayamonte. Ayamonte.

Baganha, M.I. (1994). As correntes emigratórias portuguesas no século XX e o seu impacto na economia nacional. Análise Social, 29(128), 959-980.

Baganha, M.I. (2003). From closed to open doors: Portuguese emigration under the Corporatist Regime. e-JPH, 1, Summer, 1-13.

Basch, L.; Schiller, N.; Blanc-Szanton, C. (1999). Transnationalism: A new analytic framework for understanding migration. Em S. Vertovec; R. Cohen (Ed.). Migration, diaspora and transnationalism. Edward Elgar Publishing.

Borges, M. (2009). Chains of gold: Portuguese migration to Argentina in transatlantic perspective. Leiden: Brill.

Bretell, C. (2003). Anthropology and migration: Essays on transnationalism, Etnicity and identity. Walnut Creek: Altamira.

Campos, M.C.; Rocha-Trindade, M.B. (2005). História, memória e imagens nas migrações. Oeiras: Celta.

Cavaco, C. (1971). Migrações internacionais de trabalhadores do Sotavento do Algarve. Finisterra, 6(11), pp. 41-83.

Cavaco, C. (1976). O Algarve oriental: as vilas, o campo e o mar (vols. I, II). Faro: Gabinete do Planeamento da Região do Algarve.

Costa, R. (2002). A emigração de algarvios para Gibraltar e Sudoeste da Andaluzia: 1834-1910. Lisboa: Estar.

Magalhães, J.R. (1970). Para o estudo do Algarve económico no século XVI. Cosmos.

Magalhães, J.R. (1988). O Algarve económico 1600-1773. Lisboa: Estampa. 
Marques, A.H. (1968). Introdução à História da Agricultura em Portugal: A questão cerealífera durante a Idade Média. Lisboa: Cosmos.

Moch, L.; Hoerder, D. (Ed.). (1996). Migrants. Global and local perspectives. Boston: Northeastern University Press.

Oliveira, I.T. (2007). Emigração, retorno e reemigração na primeira metade do século XX. Análise Social, XLII(184), $837-852$.

Paulo, H. (1998). O Estado Novo e a emigração: Alternativas e propostas. Máthesis, 7, 291-326. Obtido de http://hdl.handle.net/10316.2/23832

Pereira, M.H. (1981). A política portuguesa de emigração (1850-1930). Lisboa: A Regra do Jogo.

Pereira, V. (2002). l'état portugais et les portugais en France de 1958 à 1974. Lusotopie, 9-27.

Pereira, V. (2005). El poder de la impotencia. Policías y migración clandestina entre Portugal e Francia (1957-1974). Política y Sociedad, 42, 103-120.

Pereira, V. (2009). Emigração e desenvolvimento da previdência social em Portugal. Análise Social, XLIV(192), 471510 .

Rocha-Trindade, M.B. (1984). La sociologie des migrations au Portugal, In Migrations in Europe - Part 1. Current Sociology, Londres: SAGE, vol. 32, 175-198. 